\title{
A message from the President of the Society for Armenian Studies
}

In 1974, a group of scholars spearheaded the project to establish a Society for Armenian Studies: Richard G. Hovannisian, Dickran Kouymjian, Nina Garsoïan, Avedis Sanjian, and Robert Thomson. Considered as the pillars of Armenian Studies, the main objective of this group was the development of Armenian Studies as an academic discipline. Since then the aims of the Society have been to disseminate Armenian culture and society, including history, language, literature, and social, political, and economic questions; to facilitate the exchange of scholarly information pertaining to Armenian studies around the world; and to sponsor panels and conferences on Armenian studies. With access to very limited resources, this group of scholars was able to establish the foundations of a Society that would play a dominant role in developing Armenian Studies in North America and beyond. From a handful of chairs and programs that supported the initiative at the time, today Armenian Studies as a discipline has flourished in the United States with more than thirteen Chairs and Programs providing their unconditional support to the Society.

Ten years after its establishment, the Society published its first academic journal under the title of the Journal of the Society for Armenian Studies (JSAS). In 1984 the first volume appeared under the editorship of Prof. Avedis K. Sanjian (1921-1995). Since then, it has served as the foremost journal for scholarship in the field of Armenian studies in the Western Hemisphere. The purpose of the Journal, according to the inaugural editor, was "the dissemination of the best original scholarship in Armenian studies and closely related fields, without any chronological limitations."

Since 2018 the Society has embarked on several major projects in order to disseminate knowledge of the field and make it relevant to a 21st century audience. One of the most important projects was to publish the journal through a prestigious and professional publishing house. After thorough research, the Society agreed unanimously that Brill would be the desired place for publishing JSAS. The Society for Armenian Studies (SAS) is thrilled about this new partnership with Brill. There is no doubt that the Journal of the Society for Armenian Studies (JSAS) will become a leading journal in the field of Armenian Studies with a new editor, advisory and editorial boards as well as book review editors. 
We look forward to a fruitful collaboration with Brill with the aim of transforming the Journal into a global hub of disseminating knowledge about Armenian Studies. With its first female editor, Dr. Tamar M. Boyadjian, and a highly qualified scholars on the advisory and editorial boards, JSAS will open new horizons for developing as a cross-cultural and interdisciplinary field. Through Brill we are looking forward to achieving high strides in the field of Armenian Studies. I have no doubt that JSAS will soon become a prestigious journal attracting scholars from all around the globe.

Bedross Der Matossian, Ph.D.

President of the Society for Armenian Studies (SAS) 